\title{
Molecular-genetic risk assessement of determining angiotensin-converting enzyme hyperactivity in hemorrhagic fever with renal syndrome
}

\author{
Asiya A. Baygildina ${ }^{1}$, Denis V. Islamgulov ${ }^{2}$, Felix Kh. Kamilov ${ }^{1}$, Tamara A. Khabelova ${ }^{1}$, Ildar R. Minniakhmetov ${ }^{2}$ \\ ${ }^{1}$ Bashkirian State Medical University, Ufa, Russia \\ ${ }^{2}$ Institute of Biochemistry and Genetics, Ufa Scientific Centre of the Russian Academy of Sciences, Ufa, Russia
}

Accepted 10 June 2012

Original Text in Russian (C) Baygildina AA, Islamgulov DV, Kamilov FK, Khabelova TA, Minniakhmetov IR, 2010, published in Saratov Journal of Medical Scientific Research 2010; 6(1): 14-17.

\begin{abstract}
The present study was designed to investigate changes in angiotensin-converting enzyme (ACE) blood activity and angiotensin II type 1 receptor gene polymorphism as a possible disease predictor in hemorrhagic fever with renal syndrome (HFRS). Four hundred and nine patients ( 346 males and 63 females) with HFRS serologic confirmation were enrolled in the study. Their age ranged from 15 to 65 years. ACE blood activity was assessed kinetically using the Bühlmann (Switzerland) kit. Peripheral blood genomic DNA was isolated by a phenol-chloroform extraction. The genotyping of DNA loci was done using a polymerase chain reaction of DNA synthesis. Statistically, ACE blood activity was significantly higher throughout the entire HFRS course with diverse severity apart from the feverish phase of moderateto-severe uncomplicated disease forms. ${ }^{*} A 1166$ and ${ }^{*} C 1166$ alleles, ${ }^{*} A 1166 /{ }^{*} A 1166$ and ${ }^{*} C 1166 /{ }^{*} C 1166$ genotypes of angiotensin II type 1 receptor gene were not associated with HFRS severity. The results of this study indicate that high ACE activity has not adaptive characteristics due to abnormalities in angiotensin II reception. It is an adequate metabolic response of the body to endotheliotropic virus activity.
\end{abstract}

Keywords: angiotensin-converting enzyme, gene of angiotensin II type 1 receptor, hemorrhagic fever with renal syndrome.

Cite as Baygildina AA, Islamgulov DV, Kamilov FK, Khabelova TA, Minniakhmetov IR. Molecular-genetic risk assessement of determining angiotensinconverting enzyme hyperactivity in hemorrhagic fever with renal syndrome. Russian Open Medical Journal $2012 ; 1$ : 0201.

Correspondence to Asiya A. Baygildina. Address: flat 101, 18, boulevard Davletshinoy, Ufa, 450097, Russia. Phone: +7 9173484738.

E-mail: baigildinaasia@mail.ru

\section{Introduction}

The main health determinants are unmodifiable and uncorrectable risk factors. Among them, in addition to sex and age, heredity ranks first [1]. At present, the impact of hereditary characteristics on disease severity caused by physical, chemical, and biological factors is being studied to identify risk groups susceptible to disease. Over the last few years, a great number of studies dedicated to identifying genes responsible for diverse diseases development have been conducted. Some progress is being made in detecting genes involved in endothelial dysfunction that can have hereditary genesis.

Several studies have shown the association of polymorphic markers of genes encoding various components of the reninangiotensin system (angiotensin-converting enzyme (ACE) genes, angiotensinogen, angiotensin receptor II (ATII) type 1) with the development of essential hypertension [2, 3, 4], coronary artery disease [5, 6], endothelial dysfunction [7], chronic renal failure and anuria [8], etc. However, in the available literature there are no data on the effects of genetic characteristics on endothelial dysfunction caused by infectious diseases. In view of this background, the aim of this study was to investigate the activity of angiotensin-converting enzyme and gene angiotensin II type 1 (AGTR1) receptor polymorphism as a possible predictor of diverse grades of hypertension accompanied by hemorrhagic fever with renal syndrome (HFRS) - a viral disease associated with Puumala hantavirus serotype.

\section{Material and Methods}

The study was approved by the Biomedical Ethics Committee of the Bashkirian State Medical University. A total of 409 patients (346 males and 63 females) aged $15-65$ years (mean 3,6 $\pm 3,5$ years) with HFRS serologic confirmation were enrolled in this study. They had been hospitalized in Infectious Clinical Hospital № 4 in the city of Ufa and in the hemodialysis department of the Kuvatov Republican Clinical Hospital between 2003 and 2008. Patients who did not meet the entry criterion due to a history of such diseases as hypertension, heart and vascular disorders, diabetes mellitus, rheumatism, malignant diseases, liver and kidney disorders were excluded. HFRS severity was assessed by the Sirotin classification [9]. Moderate-tosevere type was diagnosed in 252 patients (61.6\%), severe uncomplicated type - in 109 patients (26.7\%), severe complicated type - in 48 patients (11.7\%). The control group consisted of 52 healthy volunteers, matching in sex and age.

ACE activity was assessed by taking $5 \mathrm{ml}$ blood samples by cubital vein venipuncture in the morning on fasting. The blood was collected into special tubes without anticoagulants and was stored for 2 hours at $18^{\circ} \mathrm{C}$, then centrifuged at $4^{\circ} \mathrm{C}$ at $1000 \times \mathrm{g}$, then the serum was collected. The tested blood serum samples were stored 
for up to 6 months at $20^{\circ} \mathrm{C}$. ACE activity in the blood serum was determined by the kinetic method using the Bühlmann (Switzerland) kit. The light absorption was recorded using the Bio-Rad (USA) 'Bench mark' ELISA analyzer. For genetic studies, venous blood samples were collected into vacutainer tubes containing EDTA. The peripheral blood DNA was extracted by phenol-chloroform extraction [10]. The AGTR1 A1166C gene polymorphism was analysed by a polymerase chain reaction of DNA synthesis and subsequent enzymatic hydrolysis with BstDEl ('SibEnzyme' Russia) restriction endonuclease. The amplification results were assessed by electrophoresis in $2 \%$ agarose gel followed by staining with ethidium bromide and visualization in the incident ultraviolet light. The amplification of the AGTR gene plot, containing an A1166C nucleotide substitution, resulted in obtaining an amplicon with a length of $225 \mathrm{bp}$. The amplicon, containing ${ }^{*} \mathrm{C} 1166$ allele, has a recognition site for restriction enzyme BstDEl, and breaks down to form products of 110 and $115 \mathrm{bp}$. in size, while the DNA fragment containing *A1166 allele remains unsplit. The presence of the 225 bp long fragment after treatment with BstDEl corresponds to ${ }^{*} A 1166 /{ }^{*} A 1166$ genotype, two fragments (110 and $115 \mathrm{bp}$ ) correspond to ${ }^{*} \mathrm{C} 1166 /{ }^{*} \mathrm{C} 1166$ genotype and three fragments (110, 115 and 225 bp) correspond to heterozygous ${ }^{*} A 1166 /{ }^{*} C 1166$ genotype.

Statistical analysis was performed using Statistica 7.0 (StatSoft, Inc., 2004) and SPSS 13 programms. ACE activity study results were assessed by the nonparametric statistics method, defining the median (Me) and the interquartile range (25\% and $75 \%)$; the accuracy of inter-group differences in mean values was evaluated by the Mann-Whitney criterion. The study results were represented as Me (Q1; Q3). Genotype frequencies, alleles in HFRS patient groups with varying degrees of severity were compared by the Pearson's criterion 2 (chi-square). For all analysis types the differences were considered significant with $\mathrm{p}<0.05$.

\section{Results}

The results of determining ACE activity in blood serum of HFRS patients show equal dependency on the disease phase and severity (Figure). The feverile phase in the moderate type is characterized by a statistically insignificant tendency to a decrease in ACE activity, other phases of this type have a statistically significant increase in enzyme activity, peaking in the diuretic phase as much as 3.1 times higher than control values. Also, a similar tendency of the parameter under discussion to changing is observed in the severe uncomplicated type. However, despite the similar dynamics, the enzyme activity in the diuretic and convalescent phases of the severe uncomplicated HFRS type reaches higher values ( 3.5 times higher than the control values) up to significant differences in the last phase, not only when compared to the control group, but also between moderate-tosevere uncomplicated types in convalescent phases. With severe complicated HFRS, the dynamics of ACE activity changing differs from other types of disease: the enzyme hyperactivity without significant fluctuations from period to period is observed during the course of disease with maximal level in the diuretic period 3.3 times higher than the control - and with a statistically insignificant tendency to a decrease in its activity in the convalescent phase. With severe complicated HFRS, ACE activity differs significantly not only from the control group, but from moderate-to-severe uncomplicated disease forms. Traditional therapy does not normilize the parameter under discussion to the convalescent phase in all HFRS severity types.
The polymorphism type, the primers' sequence and the range of alleles of the analyzed polymorphic loci of AGTR1 gene are shown in Table 1. Table 2 shows the results of estimating the distribution of alleles and genotype frequencies of the $A 1166 C$ polymorphic locus of the AGTR1 gene in HFRS patients, depending on the disease severity. In all samples studied, the distribution of genotype frequencies corresponds to the Hardy-Weinberg distribution. The comparative analysis of the genotype frequencies distribution of the AGTR1 polymorphic loci of the A1166C gene revealed no statistically significant differences between the patient groups with different types of HFRS severity ( $p>0.05)$. Patient groups with moderate-to-severe HFRS show the equivalent distribution of genotype frequencies ${ }^{*} C 1166 /{ }^{*} C 1166$ (54\% and $60 \%$, respectively).

The heterozygous genotype ${ }^{*} A 1166 /{ }^{*} C 1166$ occurred almost $10 \%$ more frequently in patients with a moderate type (42\%) than in those with a severe type (33\%). Patients with a more severe HFRS type show a two-fold increase in frequency of ${ }^{*} C 1166 /{ }^{*} C 1166$ genotype $(6,7 \%)$ than with moderate disease severity $(3.9 \%)$

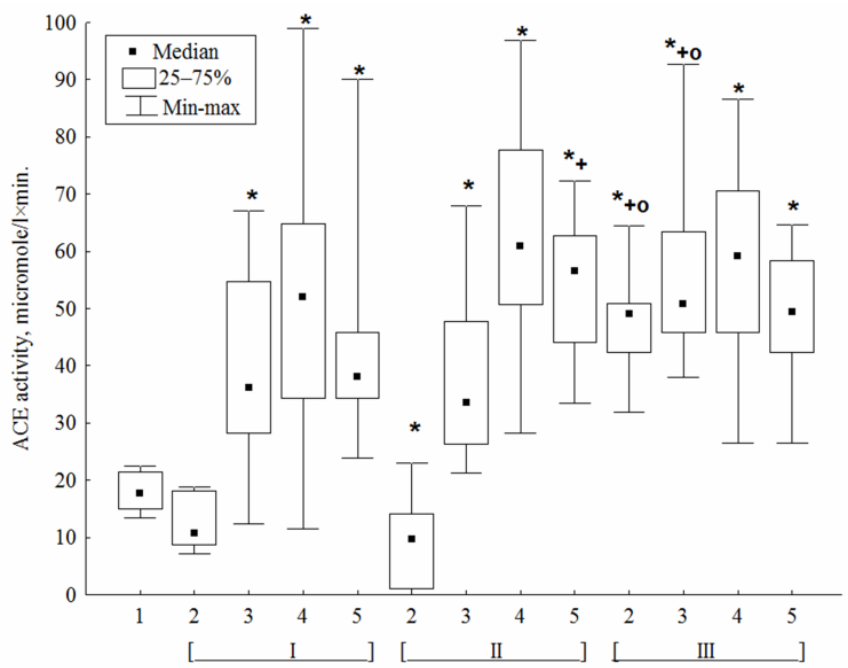

Figure. ACE activity in the serum of HFRS patients undergoing traditiona tratment.

1 is control group, 2 is feverish phase, 3 is oliguric phase, 4 is diuretic phase, 5 is convalescent phase. I - moderate type, II - severe uncomplicated type, III - severe complicated type. * is statistical significance $(p<0.05)$ of the differences with the control group; + is significance of the differences with the moderate type; $o$ is significance of the differences with the severe uncomplicated type.

Table 1. Polymorphism type, primers' sequence and range of alleles of analyzed polymorphic loci

\begin{tabular}{ccc}
\hline $\begin{array}{c}\text { Gene [OMIM], } \\
\text { localization }\end{array}$ & Polymorphism (alleles) & $\begin{array}{c}\text { Primers } \\
\text { (restrictions ferment) }\end{array}$ \\
\hline AGTR1 & A1166C & $5^{\prime}$ GCACCATGTTTTGAGGTTGA 3' \\
{$[106165]$} & ${ }^{*}$ A1166 $-225 \mathrm{bp}$ & $5^{\prime}$ TGTGGCTTTGCTTTTCTTG 3' \\
3q21-q25 & ${ }^{*}$ C1166 $-(110 \mathrm{bp}+115 \mathrm{bp})$ & $($ BstDEI $)$ \\
\hline
\end{tabular}


Table 2. Distribution of genotype and allele frequencies of the $A 1166 C$ polymorphic locus of the AGTR1 gene in patients with HFRS of different severity

\begin{tabular}{|c|c|c|c|c|c|c|}
\hline \multirow{2}{*}{\multicolumn{2}{|c|}{ Disease form }} & \multicolumn{3}{|c|}{ Genotypes } & \multicolumn{2}{|c|}{ Alleles } \\
\hline & & ${ }^{*} A /{ }^{*} A$ & ${ }^{*} A /{ }^{*} C$ & ${ }^{*} C /{ }^{*} C$ & ${ }^{*} A$ & ${ }^{*} C$ \\
\hline \multirow[b]{2}{*}{ Moderate } & $\mathrm{n}$ & 84 & 65 & 6 & 233 & 77 \\
\hline & $\mathrm{pi} \pm S p, \%$ & $54.2 \pm 4.0$ & $41.9 \pm 3.9$ & $3.9 \pm 1.6$ & $75.2 \pm 2.5$ & $24.8 \pm 2.5$ \\
\hline \multirow[b]{2}{*}{ Severe uncomplicated } & $\mathrm{n}$ & 54 & 30 & 6 & 138 & 42 \\
\hline & $\mathrm{pi} \pm S p, \%$ & $60.0 \pm 5.2$ & $33.3 \pm 5.0$ & $6.7 \pm 2.6$ & $76.7 \pm 3.2$ & $23.3 \pm 3.2$ \\
\hline \multirow{2}{*}{ Severe complicated } & $\mathrm{n}$ & 32 & 12 & 3 & 76 & 18 \\
\hline & $\mathrm{pi} \pm \mathrm{Sp}, \%$ & $68.1 \pm 6.8$ & $25.5 \pm 6.4$ & $6.4 \pm 3.6$ & $80.9 \pm 4.1$ & $19.2 \pm 4.1$ \\
\hline
\end{tabular}

$\mathrm{n}$ is absolute number of genotypes (alleles); pi is frequency, Sp is error of pi.

\section{Discussion}

The main part of ACE is normally synthesized in the vascular endothelium. About $90 \%$ of the enzyme is fixed on the endothelial plasmatic membrane, and only $10 \%$ of its activity occurs in blood plasma. The major effector of ACE is AT II. It acts via binding with specific angiotensin receptors. ATII type 1 (AGTR1) receptor is predominant. Both physiological and pathophysiological effects of the peptide including vasoconstriction, increased cardiac output, an aldosterone secretion stimulation and suppression of vasopressin production, an increase in inhibitor of plasminogen tissue activator, stimulation of the cytokine production and initiation of inflammation in the vascular wall, stimulation of active oxygen species generation, and others are produced via this receptor [11, 12]. HFRS, caused by endotheliotropic virus, is characterized by both endothelial hyperactivation and its damage $[13,14]$, which on the one hand, leads to elevated ACE expression by endotheliocytes, and on the other hand, to proteolytical splitting off the enzyme molecules from the surface of the damaged endothelial cells. This consequently brings about an increase in the plasma ACE pool. ACE feedback hyperexpression due to the absence of its pressor effect due to impaired reception of ATII cannot be excluded. We have identified significant changes in ACE activity depending on HFRS severity. The moderate type is characterized by lesser enzyme activity than in other disease types, and the enzyme activity doesn't show marked shifts in the course of disease. With severe uncomplicated type, ACE activity is extremely elevated to the diuretic phase. With severe complicated type, ACE hyperactivity is observed during the course of disease with statistically significant intergroup differences. However, the study of ATII type 1 receptor gene polymorphism has shown that both ${ }^{*} A 1166$ and ${ }^{*} C 1166$ alleles, as well as ${ }^{*} A 1166 /{ }^{*} A 1166$, ${ }^{*} A 1166 /{ }^{*} C 1166$ and ${ }^{*} C 1166 /{ }^{*} C 1166$ genotypes are not associated with HFRS severity. This suggests that high ACE activity in HFRS, which is as higher as severer the course of disease, is not caused by the impaired ATII reception due to the absence of the vascular effect and can be considered as a quite adequate response of the macroorganism to metabolic changes, primarily caused by Puumala hantavirus as an HFRS etiological factor.

\section{Conclusion}

1. The present study demonstartes a significant increase in ACE activity in HFRS patients' blood depending on the phase and severity.
2. Comparative analysis of the frequency distribution of A1166C polymorphic locus of AGTR1 gene of angiotensin II has not revealed any statistically significant differences between groups of patients with HFRS varying severity.

3. Increased ACE activity in HFRS, particularly marked in severe type, is not an adaptive reaction due to impaired ATII reception in HFRS. It is an adequate metabolic response to the invasion of an endotheliotropic virus.

Conflict of interest: none declared.

\section{Reference}

1. Stronks $\mathrm{K}$, Van de Mheen $\mathrm{H}$, Loomon CWN, Mackenbach JP. Behavioural and structural factors in health: an empirical analysis. Sociology of health and illness 1996; 18(5): 653-674 (doi: 10.1111/1467-9566.ep10934524).

2. Fan H, Li S, Gu W, Li Y, Ma H, Luo J, Wang W, Lu X. Association between angiotensin II type I receptor gene and human essential hypertension. Zhonghua Yi Xue Yi Chuan Xue Za Zhi 1998; 15(2): 101103 (PMID: 9531651).

3. Jiang $X$, Sheng $H$, Li J, Xun P, Cheng $Y$, Huang J, Xiao H, Zhan Y. Association between renin-angiotensin system gene polymorphism and essential hypertension: a community-based study. J Hum Hypertens 2009; 23(3): 176-181 (doi:10.1038/jhh.2008.123) (PMID: 18830250).

4. Palatini P, Ceolotto G, Dorigatti F, Mos L, Santonastaso M, Bratti P, Papparella I, Pessina AC, Semplicini A. Angiotensin II type 1 receptor gene polymorphism predicts development of hypertension and metabolic syndrome. Am J Hypertens 2009; 22(2): 208-214 (PMID: 19023273) (doi:10.1038/ajh.2008.319).

5. Tiret L, Bonnardeaux A, Poirier O, Ricard S, Marques-Vidal P, Evans A, Arveiler D, Luc $G$, Kee $F$, Ducimetière $P$, et al. Synergistic effects on angiotensin-converting enzyme and angiotensin II receptor gene polymorphism on risk of myocardial infarction. Lancet 1994; 344(3): 910-913 (PMID: 7934345).

6. Van Geel PP, Pinto YM, Zwinderman AH, et al. Synergistic effects of angiotensin converting enzyme and angiotensin II type 1 receptor gene polymorphisms on ischemic events. Abstract book of XX Congress of the European society of Cardiology: P. 386.

7. Berkowich OA, Bazhenova EA, Vakhrameyeva NV, et al. Gene polymorphisms of renin-angiotensin system and endothelial dysfunction in men with myocardial infarction at a young age. Arterial hypertension 2008; 14(3): 239-244 [Article in Russian].

8. Gribouval O, Gonzales M, Neuhaus T, Aziza J, Bieth E, Laurent N, Bouton JM, et al. Mutations in genes in the renin-angiotensin system are associated with autosomal recessive renal tubular dysgenesis. 
Nature Genet 2005; 37(9): 964-968 (doi: 10.1038/ng1623) (PMID: 16116425).

9. Sirotin BZ. Hemorrhagic fever with renal syndrome. Khabarovsk, Russia, 1994; $300 \mathrm{p}$ [Text in Russian].

10. Maniatis T, Fritsch E, Sembruk J. Genetic engineering methods. Molecular cloning. Academic Press, Russia, 1984; 352 p [Text in Russian].

11. Drozdova GA. Cellular mechanisms of arterial hypertension. Pathological physiology 2000; (2): 26-31 [Article in Russian].

12. Galle J, Heermeier K. Angiotensin II and oxidized LDL : an unholy alliance creating oxidative stress. Nephrol Dial Transplant 1999; 14(11): 2585-2589 (PMID: 10534493) (doi: 10.1093/ndt/14.11.2585).

13. Kamilov FCh, Baygildina AA. Vascular endothelial integrity condition in HFRS. Morphology 2008; (4): 72 [Article in Russian].

14. Kamilov FCh, Baygildina AA. The expression of VCAM-1 as a reflection of endothelial activation in HFRS. Morphology 2008; (2): 57 [Article in Russian].

\section{Authors:}

Asiya A. Baygildina - MD, PhD, Assistant Professor, Department of Biological Chemistry, Bashkirian State Medical University, Ufa, Russia;

Denis V. Islamgulov - MD, PhD, Researcher, Laboratory of human molecular genetics, Institute of biochemistry and genetics, Ufa scientific centre of the Russian Academy of Sciences, Ufa, Russia;

Felix Kh. Kamilov - MD, D,Sc., Professor, Head of Department of Biological Chemistry, Bashkirian State Medical University, Ufa, Russia;

Tamara A. Khabelova - MD, PhD, Assistant, Department of Infectious Diseases, Bashkirian State Medical University, Ufa, Russia;

Ildar R. Minniakhmetov - MD, PhD, Researcher, Laboratory of human molecular genetics, Institute of biochemistry and genetics, Ufa scientific centre of the Russian Academy of Sciences, Ufa, Russia. 